\title{
Delayed surgery for congenital diaphragmatic hernia: neurodevelopmental outcome in later childhood
}

\author{
Mark Davenport, Elise Rivlin, S W D'Souza, A Bianchi
}

\begin{abstract}
The long term neurodevelopmental outcome was assessed in 23 survivors born with congenital diaphragmatic hernia who had been managed by. an elective delay in surgical repair after a period of stabilisation. This cohort was treated in one neonatal surgical unit between 1983 and 1989 by a single team of surgeons and anaesthetists. All children underwent comprehensive neurological, developmental, and anthropometric assessment at a mean age of 56 (range 18-94) months. Two children $(9 \%)$ had major disability (one with hemiplegia and one with a lower limb monoplegia) and two further children had minor disabilities (one had partial sightedness and squint, the other squint only). The mean developmental quotient (DQ) for the group was 108 (SD 10.8) and none had developmental delay (defined as DQ $<70$ ). Infants who had spent more time in hospital, or had had a longer duration of ventilation, tended to have lower weights and lower occipitofrontal circumference centiles in later childhood. Preoperative stabilisation and delayed surgery for congenital diaphragmatic hernia is not associated with an impaired neurodevelopmental outcome.
\end{abstract}

\section{(Arch Dis Child 1992;67:1353-6)}

During the past eight years there has been a radical change in the surgical management of infants with congenital diaphragmatic hernia (CDH). ${ }^{1-5}$ Thus, in several centres, there has been a move away from the traditional policy of emergency surgical repair toward a policy of a delay in surgery until the infant is stable. This approach was instituted because of a realisation that the high mortality rates (of about $50 \%$ ) were essentially related to the severe pulmonary hypoplasia and the associated raised pulmonary vascular resistance with marked right-to-left shunting. It had been appreciated that emergency surgical repair of the diaphragm with return of bowel into the abdomen had not helped survival, and may indeed have affected it adversely.

In 1983 the policy on the neonatal surgical unit at St Mary's Hospital, Manchester, was altered principally to emphasise the management of the pulmonary hypoplasia. The infant's oxygen requirements were minimised and attempts were made, both to use available lung tissue to maximum effect, and to reduce the right-to-left shunt. Surgery was eventually offered, only after the acute phase, to those with stable pulmonary circulations whose only remaining reason for ventilation was the presence of a diaphragmatic hernia with bowel in the pleural space. Management included neuromuscular paralysis and ventilation and correction of acid-base balance or haemodynamic disturbances. ${ }^{1}$

Though earlier reports of delayed surgery for diaphragmatic hernia have been encouraging, ${ }^{2-5}$ with a trend towards improved survival, there has been no published study on the long term effects of this delayed surgery policy. This protocol implies an elective period of prolonged intensive care and resuscitation which, although apparently achieving greater survival rates, might be associated with an increased incidence of cerebral damage and later handicap. In the present study we have retrospectively examined our population of survivors after surgery with particular regard to their growth and neurodevelopmental outcome.

\section{Patients and methods}

The neonatal surgical unit at St Mary's Hospital, Manchester, is a regional centre receiving referrals from the north west of England (approximate birth rate 60000 per annum). There were 23 children who had surgery for $\mathrm{CDH}$ between 1983 and 1989 and who lived within the Greater Manchester area. They attended outpatient clinics for neurodevelopmental and anthropometric assessments which were carried out by a paediatrician (SWD'S) and a child psychologist (ER). The developmental assessment by Griffiths's mental development scales (GMDS) ${ }^{6}$ was carried out by the child psychologist who was unaware of the perinatal history or neonatal complications.

Clinical and intensive care records were examined for the time to surgery, duration and type of ventilation (intermittent positive pressure ventilation (IPPV) or continuous positive airway pressure), blood gas and $\mathrm{pH}$ measurements, complications such as persistent fetal circulation and the use of certain drugs, for example, tolazoline.

Using the GMDS a general development quotient was calculated from the mean of six subquotients (locomotor, personal/social, hearing and speech, eye-hand coordination, performance, and practical reasoning). Age to first walking was also noted. Anthropometric data was collected from each child and included height, weight, occipitofrontal head circumference, and triceps and subscapular skinfold thickness. This was expressed according to the appropriate age corrected centile group using charts prepared by $J M$ Tanner and 
Table 1 Perinatal cerebral ultrasonography and neurological disability in four survivors following diaphragmatic hernia repair

\begin{tabular}{|c|c|c|c|c|}
\hline \multirow{2}{*}{$\begin{array}{l}\text { Patient } \\
\text { No }\end{array}$} & \multirow{2}{*}{$\begin{array}{l}\text { Ultrasound } \\
\text { brain scan }\end{array}$} & \multicolumn{3}{|l|}{ Follow up } \\
\hline & & $G M D S D Q$ & Locomotor $S Q$ & Neurological findings \\
\hline$\overline{1}$ & $\begin{array}{l}\text { IVH, left hemisphere, ischaemic } \\
\text { change }\end{array}$ & 85 & 59 & $\begin{array}{l}\text { Right hemiplegia, reduced head growth } \\
\text { walked at } 18 \text { months }\end{array}$ \\
\hline 2 & IVH, dilated ventricles & 123 & 133 & Normal \\
\hline 3 & $\begin{array}{l}\text { Right and left subependymal- } \\
\text { haemorrhage }\end{array}$ & 100 & 106 & $\begin{array}{l}\text { Partially sighted and squint; walked at } \\
24 \text { months }\end{array}$ \\
\hline 4 & Normal & 108 & 114 & Left lower limb monoplegia \\
\hline
\end{tabular}

$\mathrm{DQ}=$ development quotient; $\mathrm{SQ}=$ subquotient; $\mathrm{IVH}=$ intraventricular haemorrhage.

R H Whitehouse, and D Gairdner and J Pearson (Castlemead Publications, Herts).

Data were expressed as mean (SD) or where there was a significantly skewed distribution as median (range). Similarly, differences in group means were analysed by the unpaired Student's $t$ test or the Mann-Whitney U test, as appropriate. To investigate the relationship between perinatal variables and outcome, simple bivariate correlations were used in most instances (a Spearman rank correlation coefficient $\left(r_{s}\right)$ was used if either variable was non-parametric). A $p$ value of $<0.05$ was regarded as significant.

\section{Results}

All 23 infants had symptomatic diaphragmatic hernia (21 left sided, one right sided, and one bilateral) presenting on the first day of life and had elective surgery once the pulmonary circulation had stabilised.

Twenty two of 23 infants were born at term with a mean birth weight of $3080 \mathrm{~g}$ (SD 540); the remaining infant was preterm and born at 33 weeks' gestation with a weight of $1700 \mathrm{~g}(<3 \mathrm{rd}$ centile). Surgery was performed at a mean age of 72 hours (range 5-120 hours). All infants were ventilated before and after surgery (median duration of IPPV was 7 days, range 1-35 days). Neuromuscular paralysis was used in $21(91 \%)$ of 23 infants. Tolazoline and dopamine were used in six (26\%) and two (9\%) infants respectively. Persistent fetal circulation was diagnosed clinically in six (26\%) infants. Cerebral ultrasound scanning was carried out in all the infants and a structural cerebral abnormality was detected in three (13\%) (table 1). The median duration of hospital stay was 34 days (range 12-110 days). Table 2 gives details of perinatal blood gas analysis and ventilation variables in 23 infants.

Children were examined at outpatient clinics at a median age of 56 months (range 18-94 months). Table 3 shows the neurodevelopmental outcome. Neurological (including both hearing

Table 2 Blood gas analyses and ventilation variables in 23 infants with congenital diaphragmatic hernia

\begin{tabular}{|c|c|c|c|c|c|c|}
\hline & $\begin{array}{l}p H \\
(\min / \max )\end{array}$ & $\begin{array}{l}\text { Minimum } \\
\text { oxygen } \\
\text { tension } \\
(\mathrm{kPa})\end{array}$ & $\begin{array}{l}\text { Maximum } \\
\text { carbon } \\
\text { dioxide } \\
\text { tension } \\
(\text { kPa })\end{array}$ & $\begin{array}{l}I P P V \\
\text { (days) }\end{array}$ & $\begin{array}{l}\text { CPAP } \\
\text { (days) }\end{array}$ & $\begin{array}{l}\text { Maximum fractional } \\
\text { inspiratory oxygen } \\
(\%)\end{array}$ \\
\hline $\begin{array}{l}\text { Mean } \\
\text { SEM } \\
\text { Median* } \\
\text { Range }\end{array}$ & $\begin{array}{l}7 \cdot 1 / 7 \cdot 51 \\
0 \cdot 19 / 0 \cdot 05 \\
\text { NA } \\
(6 \cdot 7-7 \cdot 4)\end{array}$ & $\begin{array}{l}6 \cdot 0 \\
0 \cdot 35 \\
\text { NA } \\
\text { NA }\end{array}$ & $\begin{array}{l}9 \cdot 2 \\
0 \cdot 55 \\
\text { NA } \\
\text { NA }\end{array}$ & $\begin{array}{l}\text { NA } \\
\text { NA } \\
7 \\
(1-35)\end{array}$ & $\begin{array}{l}\text { NA } \\
\text { NA } \\
1 \\
(0-5)\end{array}$ & $\begin{array}{l}\text { NA } \\
\text { NA } \\
80 \\
(40-100)\end{array}$ \\
\hline
\end{tabular}

${ }^{*} A$ median (range) value is quoted when the variable is significantly skewed.

$\mathrm{CPAP}=$ continuous positive airways pressure; $\mathrm{NA}=$ not applicable. and vision) examinations showed no abnormality in $19(82 \%)$. Of the remaining infants, two $(9 \%)$ had major disability (one had a lower limb monoplegia and one, right hemiplegia), and a further two had minor abnormalities (one had partial sightedness and squint; the other had squint alone).

The mean (SD) GMDS general quotient for the group $(n=23)$ was $108(10 \cdot 8)$; range $85-133$. This was derived from six subquotients: locomotor, $110(18 \cdot 3)$; personal and social, 113 $(11 \cdot 2)$; hearing and speech, $110(14 \cdot 4)$; eyehand coordination, 107 (13.1); performance, 104 (13.8); and practical reasoning, $107(14 \cdot 3)$. Analysis of variance did not show any significant difference between these subquotient means $(\mathrm{F}$ ratio $=1 \cdot 14 ; \mathrm{p}=0.34)$. There was no significant correlation between the GMDS general quotient and any perinatal variable (time to surgery, period of IPPV, blood gas analysis, length of hospital stay). The median age of walking was 12.5 months (range 10-24). There was no significant correlation between the GMDS general quotient or the GMDS locomotor quotient and the age of walking. There was moderate correlation between the age of walking

Table 3 Neurodevelopmental outcome in 23 survivors after delayed repair of congenital diaphragmatic hernia

\begin{tabular}{lll}
\hline Index & Mean $(S D)$ & Median (range) \\
\hline Time to walk (months) & NA & $12 \cdot 5(10-24)$ \\
GMDS quotient & $108(10 \cdot 8)$ & NA (101-114) \\
& & \\
Subquotients* & & \\
Locomotor & $110(18 \cdot 3)$ & NA $(100-24)$ \\
Personal and social & $113(11 \cdot 2)$ & NA $(106-120)$ \\
Hearing and speech & $110(14 \cdot 4)$ & NA (99-119) \\
Eye-hand coordination & $107(13 \cdot 1)$ & NA (98-115) \\
Performance & $104(13 \cdot 8)$ & NA (97-114) \\
Practical reasoning & $107(14 \cdot 3)$ & NA (97-120) \\
\hline
\end{tabular}

Analysis of variance $(\mathrm{F}$ ratio $1 \cdot 14, \mathrm{p}=0 \cdot 34) ; \mathrm{NA}=$ not applicable.

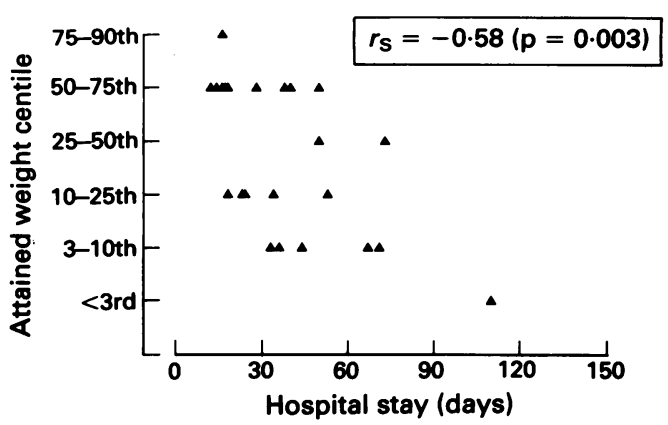

Achieved weight centile at follow up versus duration of hospital stay in 23 children after diaphragmatic hernia repair. 
and length of IPPV $\left(r_{\mathrm{s}}=0 \cdot 41, \mathrm{p}=0.05\right)$. Persistent fetal circulation in the neonatal period $(n=6)$ did not influence attained GMDS $(p=0 \cdot 1)$ or the age of first walking $(p=0 \cdot 77)$.

Height, weight, and occipitofrontal head circumference were all expressed according to age related centile charts. Thus, of 23 children, one was below the 10th centile for height, six below the 10th centile for weight, and three below the occipitofrontal 10th centile. There was significant inverse correlation between attained weight centile and both duration of IPPV $\left(r_{s}=-0.42, p=0.04\right)$ and duration of hospital stay $\left(r_{S}=-0.58, p=0.003\right.$; figure). Similarly there was an inverse correlation between attained occipitofrontal centile and duration of IPPV $\left(r_{S}=-0.41, p=0.05\right)$. There was no relationship between the attained height centile and any perinatal variable.

\section{Discussion}

$\mathrm{CDH}$ is a condition with a high mortality rate, even when treated within specialised neonatal units. ${ }^{78}$ Antenatal diagnosis gives no indication of eventual outcome. In fact, mortality rates for $\mathrm{CDH}$ may actually increase because antenatal diagnosis allows for planned delivery, close to the surgical unit, of non-survivors with severe pulmonary hypoplasia. ${ }^{9}$

The preoperative and postoperative course in these infants is characterised by episodes of reversion to the fetal type of circulation with rapid swings in blood $\mathrm{pH}$, blood pressure, and blood oxygen tensions. While the long term effects on respiratory function have been well documented in children with a history of $\mathrm{CDH}$, their neurodevelopmental outcome is not clear.

There have been several recent studies on neurodevelopmental outcome following a period of extracorporeal membrane oxygenation (ECMO) in the neonatal period. ${ }^{10-12}$ Thus Adolph et al, reviewed 57 children who had survived after ECMO for various conditions including $\mathrm{CDH}$ (although the proportion was not specified). ${ }^{10}$ Using Bayley scales of infant development (mental development index (MDI) and a psychomotor development index (PDI)) they found that $25 \%$ scored less than normal (defined as under 85 ) on the MDI while $12 \%$ scored less than normal on the PDI. There was one child (2\%) with a major neurological abnormality. If infants receiving ECMO are from a similar population to our own (that is, sustaining severe episodes of hypoxia, acid-base disturbances, and difficult ventilation) then the neurological outcome reported here appears to be similar.

The early neurodevelopment outcome in children after various types of neonatal surgery (but without ECMO) has been the subject of a previous study. ${ }^{13}$ In this, there was a significant reduction in the attained development quotient at 1 year of age in those children who had surgery as compared with control children who did not. This occurred in a heterogeneous group of infants of different gestational ages in whom surgery was carried out for various conditions such as abdominal wall defects and intestinal atresias. This study also showed that the severity of illness within the first month of life and the length of hospital stay might be followed by reductions in attained developmental scores. ${ }^{13}$ A longer term (mean age of testing 10 years) psychosocial and growth study has previously been reported in children with neonatal repair of abdominal wall defects and imperforate anus. ${ }^{14}$ These authors found a normal distribution of both anthropometric indices and developmental achievement in their population of 56 children.

The first few days of life represent a critical period during which the child with $\mathrm{CDH}$ is at risk of developing damage from hypoxia, hypercapnia, and acidosis. ${ }^{15} 16$ It has recently been determined in preterm infants (less than 32 weeks) that the presence of periventricular leucomalacia (presumed to be due to ischaemic brain injury) diagnosed in the first two hours of birth may have been acquired either antenatally or during the birth process. ${ }^{17}$ Other studies have suggested that most hemiplegias in term infants may, in fact, be of prenatal origin. ${ }^{18}$ In the present study one child had a hemiplegia and an abnormal brain scan (patient 1 , table 1 ). This child did require a prolonged period of 120 hours ventilation before surgery. The other child with a monoplegia had no obvious clinical complications which may have predisposed to brain damage. Routine ultrasound brain scans during the neonatal period had shown no abnormality. Thus, the precise time and reason for brain damage in this child is not clear. Two further infants had abnormal brain scans (table 1). One developed partial sightedness, a squint and some delay in walking, whereas the other had no detectable abnormality in later childhood.

The period of hospitalisation in our infants may have influenced their subsequent growth. The present findings suggest that infants who spent more time in hospital or required a longer duration of ventilation tended to follow a lower weight centile and a lower occipitofrontal centile in later childhood. Whether this relationship is due to the severity of their original condition or to other factors, such as early nutrition, remains speculative. Insufficient early nutrition may have played a part, as it is well known that the quality and quantity of the early diet can have a significant later effect on weight, length, and head circumference. ${ }^{19}$ It is possible that the length of stay was not in itself significant, but rather a reflection of the child's failure to establish a satisfactory weight gain. Thus, careful attention to sustained nutrition (parenteral or enteral) from an early stage might have a significant impact on long term physical outcome.

In a previous study ${ }^{1}$ we have shown that an initially conservative policy designed to overcome the life threatening consequences of pulmonary hypoplasia and raised pulmonary vascular resistance, with subsequent diaphragmatic surgery when stability has been achieved, is associated with improved survival. In this study we show that this improvement does not occur at the expense of a poor neurological outcome or development delay in the survivors. There is a suggestion from our study that 
somatic growth in survivors may be affected and, in particular, the ability to gain weight. The actual cause for this is unclear and requires further careful evaluation.

We thank Mr S J J Cohen, Miss C M Doig, and Mr D S C Gough for allowing us to study their patients.

1 Charlton AJ, Bruce J, Davenport M. Timing of surgery in congenital diaphragmatic hernia. Anaesthesia 1991;46: congen $820-3$.

2 Cartlidge PH, Mann NP, Kapila L. Preoperative stabilisation in congenital diaphragmatic hernia. Arch Dis Child 1986; $61: 1226-8$.

3 Hazebroek FW, Tibboel D, Bos AP, et al. Congenital diaphragmatic hernia: impact of preoperative stabilisation. A prospective pilot study in 13 patients. $\mathcal{J}$ Pediatr Surg 1988; 23:1139-46.

4 Langer JC, Filler RM, Bohn DJ, et al. Timing of surgery for diaphragmatic hernia: is emergency surgery necessary? f Pediatr Surg 1988;23:731-4.

5 Shanbhogue LKR, Tam PKH, Ninan G, Lloyd DA. Preoperative stabilisation in congenital diaphragmatic hernia. Arch Dis Child 1990;65:1043-4.

6 Griffiths R. The abilities of babies: a study of mental development. Amersham: Association for Research in Infant and ment. Amersham: Association

7 Reynolds M, Luck SR, Lappen R. The 'critical' neonate with diaphragmatic hernia: a 21 -year perspective. $\mathcal{F}$ Pediatr Surg diaphragmatic

8 Cullen ML, Klein MD, Philippart AI. Congenital dia-

9 Adzick NS, Harrison MR, Glick PL, Nakayama DK,
Manning FA, deLorimier AA. Diaphragmatic hernia in the fetus: prenatal diagnosis and outcome in 94 cases. $\mathcal{F}$ Pediatr Surg 1985;20:357-61.

10 Adolph V, Ekelund C, Smith C, Starrett A, Falterman K Arensman R. Developmental outcome of neonates treated with extracorporeal membrane oxygenation. $\mathcal{J}$ Pediatr Surg 1990;25:43-6.

11 Hofkosh D, Thompson AE, Nozza RJ, Kemp SS, Bowen A, Feldman HM. Ten years of extracorporeal membrane oxygenation: neurodevelopmental outcome. Pediatrics $1991 ; 87: 549-55$

12 Schumacher RE, Palmer TW, Roloff DW, LaClaire PA, Barlett RH. Follow-up of infants treated with extracorporeal membrane oxygenation for newborn respiratory failure. Pediatrics 1991;87:451-7.

13 Ludman L, Spitz L, Lansdown R. Developmental progress of newborns undergoing neonatal surgery. $\mathcal{F}$ Pediatr Surg of newborns under

14 Ginn-Pease ME, King DR, Tarnowski KJ, Green L Young G, Linscheid TR. Psychosocial adjustment and physical growth in children with imperforate anus or abdominal wall defects. F Pediatr Surg 1991;26:1129-35.

15 Weindling AM, Wilkinson AR, Cook J, Calver S-A, Fok T-F, Rochefort MJ. Perinatal events which precede periventricular haemorrhage and leukomalacia in the newborn. Br F Obstet Gynaecol 1985;92:1218-25.

16 Calvert SA, Hoskins EM, Fong KW, Forsyth SC. Etiological factors associated with the development of periventricular leukomalacia. Acta Paediatr Scand 1987;76:254-9.

17 Sinha SK, D'Souza SW, Rivlin E, Chiswick ML. Ischaemic brain lesions diagnosed at birth in preterm infants: clinical events and developmental outcome. Arch Dis Child 1990; 65:1017-20.

18 Wiklund LM, Uvebrant P. Hemiplegic cerebral palsy: correlation between CT morphology and clinical findings. correlation between CT morphology and

19 Lucas A, Gore SM, Cole TJ, et al. Multicentre trial on feeding low birthweight infants: effects of diet on early growth. Arch Dis Child 1984;59:722-30. 